\title{
Correction to: Dynamic and thermodynamic impacts of climate change on organized convection in Alaska
}

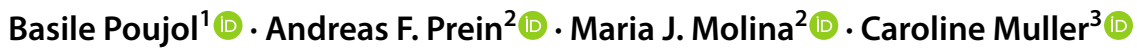

Published online: 13 April 2021

(c) The Author(s) 2021

\section{Correction to: Climate Dynamics \\ https://doi.org/10.1007/s00382-020-05606-7}

Upon publication, it came to our attention that the reference to the paper describing the underlying future WRF PGW simulation is incorrect. All references to Newman et al. (2020) should be Newman et al. (2021) and the correct citation for Newman et al. (2021) is:

Newman AJ, Monaghan AJ, Clark MP, Ikeda K, Xue L, Gutmann E, Arnold JR (2021) Hydroclimatic changes in Alaska portrayed by a high-resolution regional climate simulation. Clim Change 164. https://doi.org/10.1007/ s10584-021-02956-x.
This error does not affect the previously published results.

The original article has been corrected.

Publisher's Note Springer Nature remains neutral with regard to jurisdictional claims in published maps and institutional affiliations.

The original article can be found online at https://doi.org/10.1007/ s00382-020-05606-7.

Basile Poujol

basile.poujol@ens.fr

1 Département de Géosciences, École Normale Supérieure, PSL. Res. Univ., Paris, France

2 National Center for Atmospheric Research, Boulder, CO, USA

3 CNRS, Laboratoire de Météorologie Dynamique, Institut Pierre Simon Laplace, École Normale Supérieure, Paris, France 